\title{
A MODEL FOR INNOVATION IN HIGHER EDUCATION
}

\author{
M. Jakovljevic \\ Department of Science and Technology Education \\ University of South Africa \\ Pretoria, South Africa \\ e-mail: jakovm@unisa.ac.za
}

\section{ABSTRACT}

An extensive research and awareness about the role of innovation at education exist, but insight is missing regarding an individual frame of innovation of how to empower an individual towards life-long innovation activities. There is no adequate model that provides a holistic approach to innovation in academic institutions.

This article explores multiple innovation issues culminating in the development of a model for innovation from an individual perspective.

This article argues that awareness and the dynamics of individual innovation is missing in academic environments. Academics' engagements in innovation endeavours are scarce; there are visible symptoms of deeply embedded social, institutional, cultural and individual factors of innovation. This requires a holistic approach in innovation research.

Awareness of an individual's potential and his/her innovation development cycles, external and internal dynamics can contribute to multiple innovation sustainability. These are pillars of the ORED model (observation, revelation, exploration, design) and ever expanding cycles for innovation.

Keywords: innovation, model for innovation, higher education, innovation awareness, innovation development cycles.

\section{INTRODUCTION}

Invention streams from a creative event or sudden accidental ideas that may lead to discoveries (Johnson 1975) through investigation of the necessary sources, stimuli, actions and actors (Utterback and Abenathy 1975). Inventive ideas often leads to new markets, ventures or products (OCED 2005) but seldom encounter well-known steps such as problem identification, information gathering, idea generation, idea evaluation and idea implementation (Zhou and George 2003: cited by Jakovljevic 2013, 69).

Innovation is a process, the application of a novel or meaningfully amended creation (OECD 2005) that requires a long term commitment, resources and innovative climate within an organization (Badran 2007; Utterback 2002). Innovation requires networks of interdisciplinary players, efficient methods, and sources of funding (Haynes 2002; Kleinberg 2008, cited by Jones 2010). 
While innovation is applicable for local problems and invention is for global needs, both processes require proactive planning, a long-term oriented, development-focused and technology focused activities (Jewkes, Sawers and Stillerman 1969; Utterback 2002). However, academics seldom understand the flow between innovation and invention and the process how to develop innovative and inventive skills (Jakovljevic 2013, 69).

To promote innovative behaviour, the knowledge and awareness of construct (Neethling Brain Instruments 2000) and its potential for an application in creativity endeavours, can inevitably contribute to empowering innovative activities at higher education institutions (HEIs). Thus, nurturing innovative abilities of employees is vital in any organisation (Digman 1990).

The framework of higher education's business models helps to identify key aspects that heighten some of the universal barriers to innovation and change (Armstrong 2014). These models are not well-examined in academic contexts.

Christensen et al. (2011) and Christensen (1997, cited by Armstrong 2014) distinguished between a sustaining innovation that is absorbed into an existing business model without causing a fundamental change, and a disruptive innovation that can lead to a major change in the existing business model. Almost all disruptive proposals enthusiastically embrace new learning innovations, and optimise their new business models around one or more such innovations.

\section{PROBLEM STATEMENT}

Researchers (Sibanda 2007; Kaplan 2009; Pouris and Pouris 2011; Oanda 2013; Armstrong 2014) point out that there is a lack of an appropriate business model and foundations for producing innovation/inventions at institutions of higher education in South Africa. In spite of possessing creative knowledge, skills and a desire to produce original ideas and initiatives, academics are constrained with the work overload, insufficient modelling of innovative behaviour and inadequate funding supports (Christensen 1997; Jakovljevic 2013; Armstrong 2014).

The current programmes at HEIs should aim to develop academics' knowledge, skills and attitudes and other personality traits towards innovation. However, an appropriate model to empower innovative outcomes in HEIs is lacking in developing countries due to multiple barriers (Bedny and Seglin 1999; Lubart 2001; Badran 2007; Oanda 2013; Armstrong 2014).

Academics must be equipped with the knowledge on tools and theories for problemsolving, "big five personality model" and brain preferences constructs (Barrick and Mount 1991; Neethling Brain Instruments 2000). These issues have not been systematically examined 
and trained in academic contexts in developing countries.

\section{PURPOSE AND OBJECTIVES OF THE STUDY}

The main purpose of this study is to develop a model for innovation/invention that can drive innovative endeavours among academics. This leads to specific objectives for the study: create a theoretical framework as a basis for the proposed model; derive a model; and critically assess the model in terms of changing academic practice through applied creativity.

\section{PHASES AND RESEARCH QUESTIONS}

This study was divided into two phases: in the first phase, essential criteria were developed. Starting from the practices of innovation in South African universities (Lubango and Pouris 2009; Kaplan 2009; Sibanda 2007) the article uses criteria for innovation from phase I that were derived from the crucial issues on innovation (Jakovljevic 2018).

Based on the theoretical framework and criteria from the first phase of the study (Jakovljevic 2018), a model for facilitating innovation/invention in higher education will be developed in this article. Based on the above discussion, the purpose and objectives of the study the following research questions were derived:

1. What are the crucial components of the model for facilitating innovation/invention in higher education?

2. How do the components influence each other and how does the model influence innovation in academic environments?

Based on the collected and processed scientific literature, the researcher did a reflective analysis and synthesis in order to gain insight into the design of a model for innovation in academic environments. The method of compilation and logical methods was applied, specifying scientific data processing, and drawing conclusions and constructions of a conceptual model. The analysis of the theoretical framework, together with practical and reflective experiences, yielded a model for innovation applicable for higher education institutions (HEIs). The current theoretical framework for a model applicable for innovation will be discussed in the following sections. 


\section{THEORETICAL FRAMEWORK FOR A MODEL OF INNOVATION}

\section{Defining innovation: The core aspects of innovative behaviour}

Innovation encompasses a series of scientific, technological, organisational, financial and commercial activities (King and Anderson 2002). Three phases of innovative behaviour are highlighted in literature (Utterback and Abenathy 1975). The first phase is problem identification and idea generation. The second phase is gathering support, and the last is idea implementation. The idea generation phase of innovative behaviour is called creativity (Abdullah, Omar and Panatik 2016).

\section{Multiple perspectives on innovation}

Many perspectives on innovation exist that provide a deeper understanding of innovation and its application in academic contexts. Simonton (2003) cited by Shavinina (2003) examined "exceptional creativity across the life span". His analysis of innovation highlights the role of early experience, family background, and education professional training in developing an exceptional creative mind.

In the study of frail elderly individuals the researcher (Herzen and Vail 2003, cited by Shavinina 2003), point out that innovation doesn’t require a creative personality. An average individual in extraordinarily stressful surroundings (e.g. a need, fear, frustration, suffering, desperation, perceived treat, and possessing some internal competences and motivation) will innovate.

Innovation can be seen as a cross-disciplinary knowledge transfer (Kostoff, Carayannins, Gounzales and Wetter 2003, cited by Shavinina 2003). Innovation is a socio-technological phenomenon and an exchange of tacit knowledge that requires careful monitoring of trust.

Brain preferences construct (Neethling Brain Instruments 2000) has its potential for application in creativity endeavours. There are individual differences in terms of brain preferences, the key thinking processes and inclinations towards creativity and innovation. Academics lack adequate knowledge and training on brain preferences.

Berstein (2003) cited by Shavinina (2003) proposes the concept, “art of innovation”, as individuals differing in term of innovative initiatives and outcomes. Individuals should be inspired to detect problems in society, to develop the capability to search for real-world problems, and then solutions will follow naturally.

The neuro-physiological basis of innovation (Vandervert 2003, cited by Shavinina 2003) describes innovation as a repetitive process of working memory in the brain's cerebellum. These repetitive processes are fed back to working memory and these are experienced as new. 
As these processes are repeated the resulting degree of generalisability increases. When multiple generalizations are learned in working memory, they may give the "sudden experience of an insight and intuition”.

The psychological conception of individual innovation is a result of specific organisation of individual cognitive experiences. Innovation is seen as the understanding and interpretation of the world by constructing an individual picture of events, actions, situations, ideas, and problems that differ from other people (Shavinina 2003; Dimitrova and Chen 2006).

Multiple perspectives on innovation ("exceptional creativity across a life span”, "the art of innovation”, “innovation as a natural capability”, “innovation as a cross-disciplinary knowledge transfer”, "brain preferences”, “innovation as a sudden insight”, and "innovation as a unique construct representation” enrich the understanding of the essence of innovation. However, an integrated framework or model that incorporates these views to advance understanding of innovation is missing. How do innovative activities interact with individual needs and emotions, and why there are few discoveries in academia?

\section{A well-being society: A basis for innovation}

A well-being society provides a foundation for maintaining the growing spirit of innovation (Helliwell and Putnam 2004). In reverse, innovation translates knowledge into economic growth that contributes to a well-being society (Paul and Heckscher 2007; Grief 2016). Innovators should know the basics of a well-being society and innovation development approaches.

The private sector, civil sector, public sectors and individuals contribute to a well-being society. The degree of the development and harmony between these major sectors influences the innovative activities of a well-being of society (OECD 2011; 2012). An improved understanding of a well-being society has multiple sustainability benefits on innovation, namely, it allows organisations to improve their working environments; develop better living environments, policies and institutional rules; promote organised government initiatives; and provide the opportunities for developing high value-added innovations (Varis 2007; Geoff 2009; Berggren and Trägardh 2011).

The presence of multiple opportunities within a well-being society contributes to sustainable innovative behaviour (Berggren and Trägardh 2011; OECD 2011; 2012; EU 2013). There are various benefits in a well-being society, namely, peer-to-peer networks, cooperative publicprivate-people partnerships, encouragements of local experimentation, and innovation with an emphasis on technological innovations (Hämäläinen 2007; 2013).

Social well-being offers a wide spectrum of social media networks or social enterprises in 
a well-being society (Bourdieu 1989). The basic principle that underlies these networks is that if a large number of people with a diverse range of points of view contribute to the innovation process, the chances of creating ideas is dramatically enhanced. However, engagements are not always private and some communications present distractions for innovative efforts (Engeström 2005).

To promote innovative behaviour, different viewpoints and facets of innovation (societal, institutional and managerial) should be analysed simultaneously, in an all-inclusive way (OECD 2005; 2011; Cusumano 2010; Olakitan 2011).

\section{Institutional innovation}

\section{Some models of innovation}

Contemporary innovation research informs us of models and the nature of innovation and its basic facets:

a. TAR model - The well-known teaching-administration-research (TAR) model needs reexamination, because it hides innovation as the paramount component of university survival. It is known in practice that this TAR triangle highlights the routine tasks, which cause constant interruptions of innovative actions.

b. A stakeholder model - Besides empowering individuals and local communities, $a$ stakeholder model can support innovation and product improvements by diversifying and deepening the organisation's knowledge base (Burkitt and Ashton 1996).

c. The structural model - The structural model attempts to either simplify the system and reduce the cognitive burden of individual decision-makers, or make the overall governance structure more sophisticated and complex, that is, a better match with the increased complexity of the system (Hämäläinen 2007; Postiglione 2011).

d. Governance structured models can be developed by creating working environments and cooperation arenas that support intensive communication among experts with intermediate levels of knowledge diversity (e.g. Hämäläinen 2007; Postiglione 2011). Such boundary-crossing organisational arrangements increase the diversity of the system by fostering radical new insights, inventions and incremental innovation.

e. Triple helix and quadruple helix innovation models: The successful innovation environment requires a "triple helix" of academic-industry-government relations (Rangaa and Etzkowitz 2016). New approaches expand the "triple helix" model to the "quadruple helix innovation” model (Afonso, Monteiro and Thompson 2016; Razak and Saad 2007), 
which includes academia and technological infrastructures, firms of innovation, government and civil society.

Models of innovation, however, appear to overlook the significance of the tacit dimension of knowledge especially that is associated with external advances in scientific knowledge (Senker 2016). Also, there is no individual perspective on innovation in a wider social context.

\section{Building the successful innovation environment}

Multiple factors and networks form a complex interplay in contributing to innovation in university contexts, namely:

The university innovation culture is composed of values and beliefs of university top management, faculty, researchers, students, and administrative staff, based on tradition and communicated verbally and nonverbally (Hage and Meeus 2006; Christensen et al. 2011). The innovation culture of an organisation is as a prerequisite for innovation (Amabile et al. 1996; McLean 2005) but there is no guarantee that an innovation culture will lead to innovation.

Infrastructure: The virtual and physical infrastructure of the university should provide a direct access to the latest information related to education, research, entrepreneurship and innovation, provision of facilities, and support for start-up companies and other entrepreneurial activities (Hollinsworth 2006; Amabile et al. 1996; Bourdieu 1989; Christensen et al. 2011).

Human resources: The intensive participation of different agents, such as teachers, students, researchers, administrative and managerial staff play crucial roles in contributing to the development of an innovative benchmark with interdisciplinary collaboration (Haynes 2002; Jones 2010).

Research staff: There should be an incentive programme in place to reward research that produces innovation and transfer of knowledge to society (Hage and Meeus 2006).

Policies and regulations: the innovation policy encourages researchers to take part in the setting up start-up of their own spin-off companies (Bartell 2003; Brewer and Tierney 2010). What are existing HE policies that speak to innovative thinking?

University management and strategy: Management staff should have an innovative entrepreneurial approach to education and research. They can launch adequate grading and reward systems for innovative initiatives, support staff and students in establishing their own business and the foundation of development laboratories (OECD 2011; Laursen and Salter 2006; Christensen et al. 2011). 


\section{Higher education policies and innovative thinking}

Kruss (2005; 2010) points out that policy in South Africa expect HEIs to emphasise crosssectoral coordination with industry and knowledge networks interventions within a national system of innovation. Multiple government organisations focus on innovation developments in higher education, e.g. Science, Engineering and Technology Institutions (SETIs), the National Advisory Council on Innovation (NACI), the South African Department of Science and Technology, the Department of Trade and Industry that supports joint industry-academic research initiatives (OECD 2013) and knowledge economy (Kahn et al. 2012).

Furthermore, the National System of Innovation (NSI) highlighted the causal relationship between scientific activity and economic performance, aiming for innovation as "the centrepiece of all scientific and technological efforts” (Manzini 2012). On the other hand, there are no tax incentives for $\mathrm{R} \& \mathrm{D}$ and levels of direct government support for innovative initiatives are lacking (OECD 2017).

\section{IP practice at academic institutions in developing countries}

Intellectual property (IP) policy and procedures are managed according to the institution's core values, mission, business model and innovation practices (Sibanda 2007; Woodman, Sawyer and Griffin 1993). A well-constructed system for IP is crucial to obtaining full value and creating an intangible asset portfolio (Sharma, Kumar and Lalande 2006). Sustainable innovation depends on in-depth knowledge of IP procedures (Haynes 2002; Badran 2007).

There are multiple reasons why university research in South Africa does not generally result in IP registration. These include: unfavourable ownership provisions of the IP Act and the university's IP policy; stakeholders have little or no knowledge of the terms and provisions of the legislative mandate; IP registration and exploitation/commercialisation was not viewed as a primary goal of research; novelty is destroyed by publication; the lack of an audit committee to identify inventions; supervisors and researchers are unable to identify the potential intellectual property rights arising from students' or their own research; and uncertainty as to whether research work could result in intellectual property registration (Sibanda 2007). Also, universities need to examine their IP practices in relation to their business model.

A lack of innovation awareness, and a deprived familiarity with IP practices is visible in other developing countries (Oanda 2013). IP practices are based on inadequate economic infrastructure in developing countries that reflect strong beaurocratic procedures that may slow down the process of innovation integration in higher education. Due to absence of innovation awareness, most of the important decisions are taken by state officials rather than by elected representatives. 


\section{Higher education's business model: rethinking academic innovations}

Higher education institutions, especially universities, are notoriously resistant to change. In 2000 the United States had a huge lead over other Organization for Economic Cooperation and Development countries (OECD 2012) in academic patenting (Garrison and Kanuka 2004, 103).

Higher education's business model helps to identify key aspects of innovation (Armstrong 2014). Financial considerations and a mind-set make most institutions resistant to major change, as well as the complicated role of the faculty, which enables them to exert unusual control over change (Christensen et al. 1997; Armstrong 2014). As a result, innovations that decrease the key role of a traditional faculty tend to find little acceptance. It is too optimistic to think about a fundamental change in the institution business model that can reflect innovative practice, as there are huge demands for funding, knowledgeable resources and an appropriate infrastructure for innovation (Moses et al. 2008; Oanda 2013). Although commercial success in the USA and Canada has resulted in South Africa launching technology transfer and commercialisation support programmes (Heher 2006, 411), its slow effect on innovative initiatives is evident.

Great institutions respond with "thoughtfulness and creativity, driven by a compulsion to turn unrealized potential into results ...” (Collins 2001, 162). Given the financial constraints that exist in higher education institutions, the continuation of institutional support for technology transfer and innovation is likely to be at risk, unless external support or stimuli are provided (Heher 2006, 411). Accreditation encourages and manages sustaining innovations (Sherry 2003). Institutions are carefully rethinking their undergraduate experience, drafting policy to guide technological innovation and cautiously developing prototypes that will preserve the traditional values of higher education (Garrison and Kanuka 2004).

\section{Personality traits and innovation}

Personality has been conceptualised from a variety of theoretical perspectives, and at various levels of abstraction or breadth (McAdams 1995; Barron 1968). A widely accepted personality framework is the "big five personality model”, which contains five personality traits, namely, extraversion, agreeableness, conscientiousness, neuroticism and openness to experience (Barrick and Mount 1991; Rothmann and Coetzer 2003). Individuals with a high extraversion trait are considered to be more creative with more intuition and many divergent ideas (Costa and McCrae 1985; Digman and Inouye 1986; Stavridou and Furnham 1996; McCrae and Costa 1997; Wolfradt and Pretz 2001; Furnham and Bachtiar 2008).

Feist (1998) points out that a creative individual is high in autonomy, more ambitious, 
hostile, dominant, impulsive, confident, extravert and open to new experiences. McCrae and Costa (1987) supports the relationship between openness to experience and personality and creativity. A number of other researchers (McCrae and Costa 1997; Rogers 1961; Wolfradt and Pretz 2001; Olakitan 2011) confirmed this relationship.

According to McCrae and Costa (1987), openness can be described as the willingness of an individual to work on new ideas, curiosity, exploration of the world and others inner ideas. Sung and Choi (2009) agree with the opinion of McCrae and Costa (1987) and they pointed out that people with outgoing personalities and openness to experience have a significant impact on performance, because their absorption of information affects and improves innovation performance. From the literature it is clear that a list of innovative personality traits is growing, but there is no generally accepted personality framework for innovation.

\section{Enabling academics' innovative capabilities for sustainable innovations}

Nurturing the innovative abilities of employees is vital in any organisation (Digman 1990; George and Zhou 2001; UN 2015). Amo and Kolvereid (2005) pointed out that employees' intrapreneural personality has a significant impact on innovative behaviour. Chen, Wu and Chen (2010) found that three personality traits - agreeableness, extraversion and openness to experience - positively correlated with idea generation and idea promotion stages of innovative employee behaviour.

Creative scientists tend to be more emotionally stable, venturesome, and self-assured than the average individual (Cattell 1971, 411, cited by Barron and Harrington 1981, 18). Core creative characteristics encompass "a fairly stable set of features, e.g. intuition, self-confidence, and ability to resolve antinomies or to accommodate apparently opposite or conflicting traits in one's self-concept, a firm sense of self as creative ...” (Barron and Harrington 1981, 15). Creative scientists can act as "knowledge intermediaries" by sharing knowledge across disciplines and institutions (Jakovljevic 2013). They can be organised into interdisciplinary teams that may interact formally or informally (Meso and Smith 2000, cited by Jakovljevic 2013, 9) with entrepreneurs and contribute to their successful innovation capacities (e.g. the internal characteristics of entrepreneurs, management strategies, access to finance, external linkages and collaborations for the adoption of new technologies) (Varis 2007).

In summary, literature analysis provides a background on the following facets of innovation in higher education: core aspects of innovative behaviour, multiple perspectives on innovation, a well-being society, institutional innovations and current university models, rethinking academic innovations, IP practice, innovative personality framework, and enabling academics’ innovative capabilities. 


\section{CRITERIA FROM PHASE I OF THIS STUDY}

The criteria derived in phase I of this study supplement the theoretical foundation for the model of innovation. The following criteria are critical for innovative initiatives to succeed:

- The development of the right policies, infrastructure and a business model for innovation at an academic institution;

- Provision of constant stimuli for academic valorisation and encouragement for innovation;

- Instituting opportunities for engagement in a multidisciplinary, interdisciplinary and transdisciplinary (MIT) environment; axiom design (AD), theory of the resolution of invention-related tasks (TRIZ), homological inventive transfer (HIT), ICT and immersive technology;

- $\quad$ Creation of awareness programmes and a taxonomy on innovative personality traits;

- $\quad$ Redesigning policies on teaching load, establishing administrative and incentive supports for inventive steps;

- $\quad$ Encouragement and support in forming academic communities of practice;

- $\quad$ Nurturing multiple collaborations and developing a new pedagogy of innovation;

- $\quad$ Development of a funding policy and support in synergy with industry (Jakovljevic 2018; Shelton and Arciszewski 2007).

\section{THE MODEL OF INNOVATION IN HE: OBSERVATION, REVELATION, EXPLORATION, DESIGN (ORED)}

\section{The ORED model cycles and components}

The model is presented in the form of successive cycles with its components that are variable. More components can be placed within cycles as they are expandable. Some components are fundamental (e.g. a well-being society) and cannot be easily influenced. Some components are optional, for example, choice of technologies. The following cycles of innovation process, along with its components, are presented below:

- Cycle I: A society (a well-being society, peer-to-peer networks, culture family, education);

- Cycle II: Personality traits, resources (infrastructure, human resources, 
interdisciplinary work environment, business model, IP, innovation culture, the “quadruple helix innovation” model, management);

- $\quad$ Cycle III: Drive, stimuli, reflections, idea recording;

- Cycle IV: Criteria from phase I - Know-how patenting, academic communities of practice, TRIZ, ICT, HIT, technologies, brain preference, and collaboration;

- Cycle V: Drive, problem search, actions, explorations, actors search, initial proposal

- Cycle VI: Observation (the innovator detects a problem/need in the environment and activates the innovation process); Revelation (the innovator searches for an "inventor space” and time in order to visualise and record a novel idea followed with sketches and brief descriptions); Explorations (the innovator explores current knowledge related to the novel idea, examines market needs); Design (the inventor continues to construct novel arguments, selects and designs a technology, completes initial drawings, devises preliminary claims). See Figure 1.

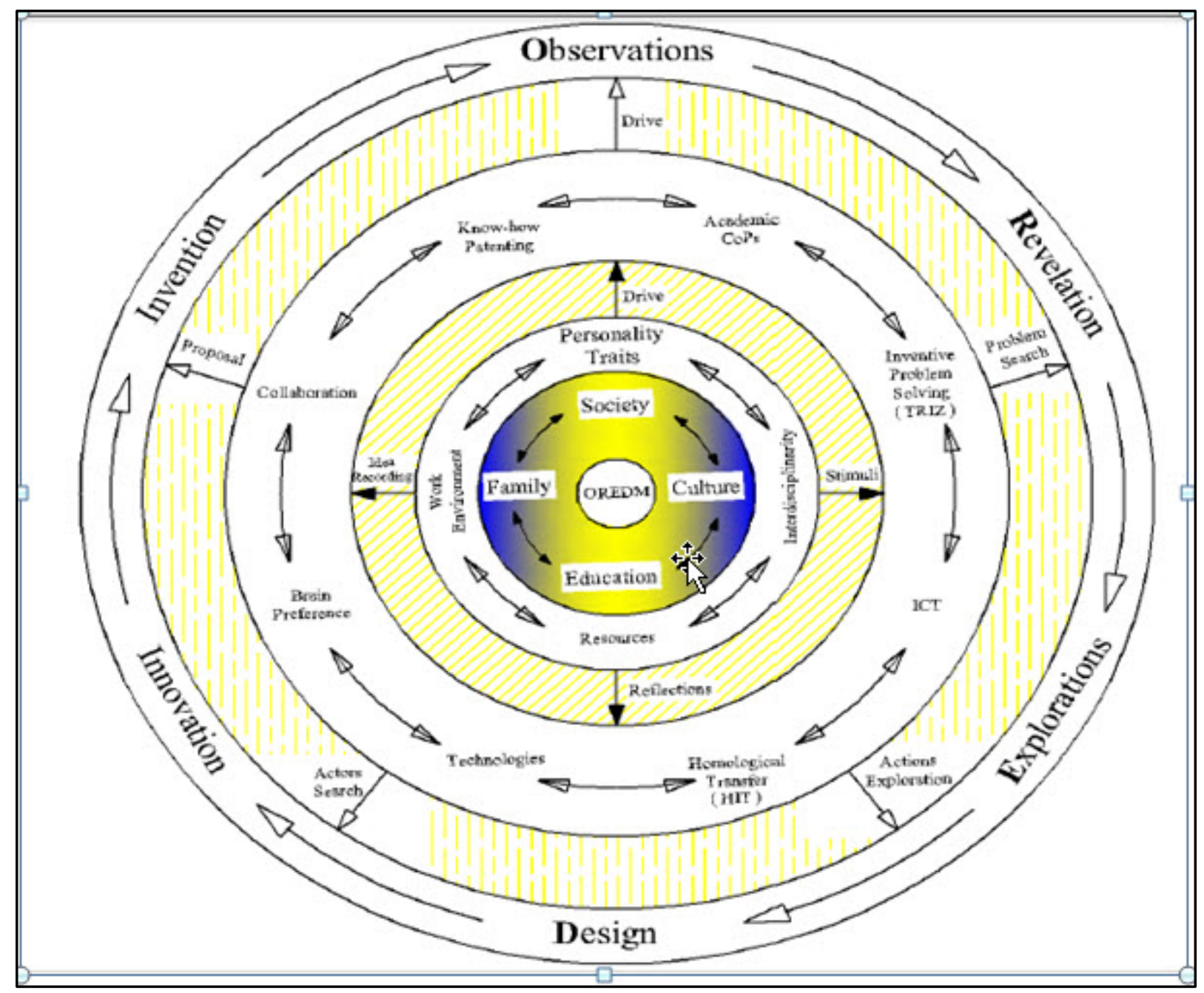

Figure 1: The ORED model for innovation in higher education 
Cycles enlighten the individual innovative process flow based on a wider support from society, family and institutional work environments. A novel design and a solution to a real-world problem are geared by an internal drive for creativity through the cycles (see Figure 1). The cycles support the natural creativity pathway allowing academics to experience the realm of creation.

\section{ORED model structure and flow: Individual innovative framework}

An individual pathway to innovation reflects an insight into an inherited capacity for creativity, unique individual innovation processes, and their common foundations.

The success of innovation depends on multiple components, their interplay and successions (see Figure 1). An individual is exposed to multiple factors that he or she should be aware of during the process of innovation (Amabile et al. 1996; McLean 2005; Hollinsworth 2006; Brewer and Tierney 2010; Christensen et al. 2011). In this way, selfmonitoring of the innovation process should be encouraged. The model is flexible and it can help to control own innovation processes and identify barriers. Through the model, individuals further develop their personal innovative capabilities and traits, based on opportunities provided by the family, societal environment, and work environments (Simonton 2003, cited by Shavinina 2003).

The innovation capabilities of individuals have roots in a well-being society, the family, schooling, and work environment (Engeström 2005). An individual will spontaneously radiate sparks of creativity until it is either choked or energised within innovation cycles that ultimately lead to a novel output. Social and institutional environments should be adequate in order to maintain individual sparks of innovation (see Figure 1).

Each building block of the model contributes to sustainable innovation and must be fairly well-understood and enriched to help an individual to accomplish multiple innovation outputs. All stakeholders have their place in the model (e.g. academics, managers, students, funders, industry partners, research collaborators).

An individual goes through the cycles even if she or he is not aware of the whole innovation process. The cycles are constantly expanding, bringing more factors that contribute to the repetitive process of "sudden experience of an insight and intuition" (Vandervert 2003, cited by Shavinina 2003), and finally to sustained innovative outputs. The model helps to understand internal, often invisible, political factors within academic institutions that inhibit inventive activities. 


\section{Summary of the ORED model}

The aim of the study was to build a model that could release an academic sustainable spirit of innovation towards solving real-world problems. The ORED model presents the flow of an innovation process that forms an individual frame of innovation. This is based on the foundations of a well-being society, institutional innovation, innovation culture, innovative personality frame, knowledge expertise, technologies, resources, and finally the innovation spirit that should be nurtured towards sustainable innovative outputs.

The individual framework of innovation is not explicitly taught in HE and academics have a fragmented picture of their own innovative processes and therefore cannot successfully complete all cycles of innovative activities. An individual possess his/her own innovative framework that is unique and the institution, with its innovation facets and opportunities, plays a crucial role in training, supporting and coordinating individual capabilities towards multiple innovations (Haynes 2002; Laursen and Salter 2006; OECD 2011).

In a well-being society and a positive work innovative climate, with appropriate stimuli and resources, academics use their own innovative drive and successfully accomplish the cycle of observation, revelation, exploration and design that leads to an innovative output.

Since academics seldom produce innovation of a broader aspect at South African universities and in other developing countries, it means that crucial aspects are missing. According to Sibanda (2007) and Oanda (2013) the need for survival is overwhelming in developing countries and there are no adequate resources to support innovation.

Each component in the ORED model is integrated with proceeding and successive cycles and works in a synergy. The model is in its preliminary stage and it can grow in its complexity. The model has a tendency to expand and additional cycles can be added with emerging external and internal factors of innovation.

In summary the ORED model presents a basic innovative life cycle and an individual should be responsible for self-monitoring and maintaining his/her innovative capability. Institutions are responsible for initiating awareness programmes, developing training methods, and ensuring human resources in order to maintain and monitor the innovative cycles of academics. It is necessary to expand an individual's awareness of his/her own enormous capacity for innovation, which higher education institutions keep captive.

\section{DISCUSSION}

This article argued that the lack of practical guiding steps, coordination and fragmented innovative actions of academics in South African and other developing countries' universities are symptoms of inadequate social well-being, a lack of university innovative infrastructure, 
and ineffective management.

In this article, multiple innovation aspects (Bourdieu 1989; Martins and Terblanche 2003; Postiglione 2011) are analysed leading to the derivation of a preliminary model that could serve as a critical aid in empowering academics to participate in innovative activities. Thus, the ORED model was derived through a combination of theoretical, practical and reflective experiences in an attempt to understand the impact of multiple factors on technology-enhanced innovation in higher education.

The literature review indicates that the dynamic intersection of numerous innovation facets, and the flow of individual innovation activities, based on societal and institutional innovation infrastructure; underpin the success of an innovation endeavour (e.g. Varis 2007; Berggren and Trägardh 2011). Furthermore, the internal drive for creativity flourishes within an innovative university culture that provides formal and informal support, human factors, training and sustainability for inventive activities and outputs (e.g. Hage and Meeus 2006).

The first research question seeks to determine "the crucial components of the model for facilitating innovation in Higher Education”. The ORED model introduces 6 cycles and 30 components including: a society well-being, peer-to-peer networks, family, education; business model, IP, innovation culture, human resources, the "quadruple helix innovation" model, management, personality traits, stimuli, innovative reflections, problem search, knowledge sharing, know-how patenting, academic communities of practice, TRIZ, ICT, HIT, technologies, brain preference, collaboration; innovative drive, action search, activities search, initial proposal; observation, revelation, exploration, design (as an answer to research question one).

The second research question seeks to determine "How do the components influence each other and how does the model influence innovation in academic environments? Providing adequate support to academics within six cycles and fostering natural innovation processes can lead to sustainable innovation at academic institutions. The individual innovation perspective was missing in the literature. In comparing the literature findings with reflection and analysis of innovation facets within the model, it is possible to conclude that university environments in developing countries need a shift toward "innovation in mind”. Furthermore, academics can benefit from the formation of ORED model in respect of its stakeholders' knowledge sharing and the exchange of novel design ideas, to create a culture of innovation (as an answer to research questions two).

Societal framework such as government, institutions, community, industry, and innovation businesses should be connected with the common aim of "innovation in mind". The level of this connectivity will influence the institutional innovation business model 
development and provide a solid foundation for academic innovation.

Societal well-being traces and empowers the innovative activities of an individual throughout his/her life cycle and can promote or prevent full innovation growth from early schooling, family environment, cultural surroundings and work environments.

Well-being societies provide a fertile foundation for individual, group and institutional higher order activities (Helliwell and Putnam 2004; Grief 2016) since basic human needs are mostly satisfied in such societies. Universities in developing societies like South Africa are oriented towards basic research, teaching with a poor administration and communication practices. A well-being society with its wide networks is an engine for innovation transformation processes. The next section presents the most important conclusions and recommendations of this article, as well as remarks for further research.

\section{CONCLUSIONS AND RECOMMENDATIONS}

The article explored theoretical and practical viewpoints on multiple factors in forming an innovative culture in higher education. In summary, an in-depth analysis of literature and current innovation practices at universities revealed the following:

- $\quad$ Social well-being - influences a need for a social awareness programme that helps to empower the innovative potential of academics. Knowing strengths and weakness of their own society helps innovators to find the right funders, to create healthy social networks, to improve working environments with innovative elements, and to create informal innovative networks aimed towards constant scientific and technological discoveries.

- University business model - cannot be copied from another university with a long tradition and a distinct social well-being, without a systematic analysis of innovation facets. It can be shaped from existing circumstances using the "quadruple helix innovation” model and consistent nurturing of individual incremental innovations.

- Different facets of innovation - the part of an awareness programme that provides dynamic and expanding perspectives on innovation that includes psychological, neurophysiological, knowledge management, and the societal and technological side of innovation. The psychological perspective on innovation includes awareness, recognition and training (ART) frame.

- Personality innovation framework - includes various personality characteristics for innovation. These characteristics are constantly developing from an early age, but need to be trained in the university context. 
- Innovative university extended triangle - universities are transforming from the teachingadministration-research triangle (TAR) to a more complex form of teachingadministration-research-innovation (TARI). Individual aspects of innovation are falling under institutional responsibility that furthermore takes care about academics' capacity and productivity.

- IP policy and practice - is a determinant of innovative behaviour ensuring that a novel idea passes all steps towards commercialisation. Knowledge of patenting requires practical training (e.g. how to provide proof of a concept, how to compile claims, and the technical side of a patent application).

- Human resources - different roles and responsibilities are considered from stakeholders including fulfilling administration and communication needs. Managers drive towards the completion of innovative outputs, routing the process and providing encouragement.

- University innovation unit - A division is missing at academic institutions that will activate, coordinate and monitor individuals and groups at university towards innovative outputs.

- University innovation culture - consistent application of a climate for innovation in all aspects of university life and activities. This can be performed by examining the flexibility of a teaching load, forming a trusting atmosphere, promoting academic freedom (without an autocratic reporting of research topics), organizing inspirational practical seminars, and creating academic communities of practice.

- $\quad$ Criteria on innovation - devised criteria from phase I of this study should be incorporated and further developed to enrich and expand the holistic view on innovation activities at universities.

- $\quad$ Motivating, monitoring and coordinating innovation - innovative outputs and discoveries will not flourish in spite of the powerful business model and IP polices, if motivating, monitoring and coordinating individual innovative behaviour is not in place as a crucial part in the ORED model.

In summary, the following are suggested:

i. A shift in the policy of innovation is required with a view to constructing an appropriate university innovative infrastructure.

ii. Universities must have strategies for evaluating, managing and coordinating innovation initiatives. 
iii. Training should be provided that helps an inspiring academic to develop self-monitoring innovation strategies.

iv. Every university should have innovative networks that are focused on the university's unique mission for innovative knowledge exchange.

v. The participation of management is essential in bringing about an increase in innovation awareness and training.

vi. A vigorous interplay between 30 components of the model at universities promotes the success of innovation endeavour.

Academics are performing many diverse tasks that are in conflict with innovation tasks that characterise the necessity for continuity, reflections, flexibility, and a block of time during innovation activities. With this innovative practice over a longer period of time an individual can be limitlessly innovative, making more complex innovations. A physio-psychological view on innovation interprets the innovative process as the "sudden experience of an insight and intuition”. Any interruption during this internal process causes a delay and a restart of the process and possible a loss of insight and intuition.

The article provided arguments for how to improve academic innovation environments by introducing the ORED model with several components, namely, awareness of a well-being society, the business model, university innovative climate, IP policy and practice adjustments, interdisciplinary perspectives on innovation, and a personal innovative framework. These and other relevant aspects represent the actual reasons for the slow advancement of innovation in university environments.

Therefore, innovation activities (scientific, technological, organisational, financial and commercial) should be carefully planned, coordinated and operationally managed. From here, a shift to the rethinking and restructuring of university innovation practice should occur.

\section{Originality/value and future research}

The originality and the value of this research lie in displaying the impact of establishing a formal model of innovation based on a solid theoretical framework in academic environments. There is, in general, a lack of research in this area, particularly in terms of understanding innovation from an individual's point of view.

Furthermore, this research reports on the analysis of multiple innovation facets in South African academic institutions. It also provides insight into developing pedagogy of innovation; provides 30 factors of innovation within 6 cycles and extends the "quadruple helix innovation" model (academia, technological infrastructures, firms of innovation, government, and civil 
society) to "innovators society". This study will be of value to academics in higher education, knowledge networks researchers and educators at institutions of higher education.

Although the theoretical framework and the model ascertain crucial aspects of innovation in higher education, this study is narrow in terms of HE practice. It therefore requires practical examinations to determine how the model can be realized in academic environments. The components of the model need careful examinations and measureable performance indicators which warrant further analysis.

\section{REFERENCES}

Abdullah, I., R. Omar and S. A. Panatik. 2016. A literature review on personality, creativity and innovative behaviour. International Review of Management and Marketing 6(1): 177-182.

Afonso, O., S. Monteiro and M. Thompson. 2016. A growth model for the quadruple helix innovation theory. http://www.fep.up.pt/investigacao/working papers/10.04.22_wp370.pdf (Accessed 4 December 2016).

Amabile, T. M., R. Conti, H. Coon, J. Lazenby and M. Herron. 1996. Assessing the work environment for creativity. Academy of Management Journal 39(5): 1154-1185.

Amo, B. W. and L. Kolvereid. 2005. Organizational strategy, individual personality and innovation behaviour. Journal of Enterprising Culture 13(1): 7-19.

Armstrong, 1. 2014. Barriers to innovation and change in Higher Education, 1-13. University of Southern California, TIAA-CREF Institute. http//www.tiaa-crefinstitute.org/ (Accessed 28 July 2016).

Badran, I. 2007. Enhancing creativity and innovation in engineering education. European Journal of Engineering Education 32(5): 573-585.

Barrick, M. R. and M. K. Mount. 1991. The big five personality dimensions and job performance: A meta-analysis. Personnel Psychology 44(1): 1-26.

Barron, F. 1968. Creativity and personal freedom. Princeton, NJ: Van Nostrand.

Barron, F. and D. M. Harrington. 1981. Creativity, intelligence, and personality. Annual Reviews Psychology 32: 439-476.

Bartell, M. 2003. Internationalization of universities: A university culture-based framework. Higher Education 45: 43-70.

Bedny, G.Z. and M. H. Seglin. 1999. Individual features of personality in the former Soviet Union. Journal of Research in Personality 33: 546-563.

Berggren, H. and L. Trägardh. 2011. Social trust and radical individualism. In the Nordic way: Shared norms for the new reality. World economic Forum, Davos.

Bourdieu, P. 1989. Social space and symbolic power. Sociological Theory 7(1): 14-25.

Brewer, D. and W. G. Tierney. 2010. Barriers to innovation in U.S. higher education. Paper presented at the conference on Higher Education Innovation at the American Enterprise Institute.

Burkitt, B. and F. Ashton. 1996. The birth of the stakeholder society. Critical Social Policy 16(49): 112.

Chen, S. C., M. C. Wu and C. H. Chen. 2010. Employee's personality traits, work motivation and innovative behaviour in marine tourism industry. Journal of Service Science and Management (02): 198.

Christensen, C. M. 1997. The innovator's dilemma: When new technologies cause great firms to fail. Boston, MA: Harvard usiness School Press. 
Christensen, C. M., M. B. Horn, L. Caldera and L. Soares. 2011. Disrupting college: How disruptive innovation can deliver quality and affordability to postsecondary education. Centre for American Progress and Innosight Institute. https://www.americanprogress.org/issues/economy/reports/ 2011/02/08/9034/disrupting-college/ (Accessed 3 February 2017).

Collins, J. 2001. Good to great: Why some companies make the leap ... and others don't. New York: Harper Business.

Costa, P. T. and R. R. McCrae. 1985. The NEO personality inventory manual. Odessa, FL: Psychological Assessment Resources.

Cusumano, M. A. 2010. Staying power: Six enduring principles for managing strategy and innovation in an uncertain world. Oxford: Oxford University Press.

Digman, J. and J. Inouye. 1986. Further specification of the five robust factors of personality. Journal of Personality and Social Psychology 50(1): 116-123.

Digman, J. 1990. Personality structure: Emergence of the five-factor model. Annual Review of Psychology 41: 417-440.

Dimitrova, D. and Y. Chen. 2006. Profiling the adopters of e-government information and services: The influence of psychological characteristics, civic mindedness, and information channels. Social Science Computer Review 24: 172-188.

Engeström, J. 2005. Why some social network services work and others don't - or: the case for objectcantered sociality. http://zengestrom.com/blog/2005/ 04/why_some_social.html (Accessed 20 October 2008).

EU Commission, Directorate-General for Research and Innovation. 2013. Options for strengthening responsible research and innovation on the state of art in Europe: responsible research and innovation, Report of the Expert Group on the State of Art in Europe. Luxembourg: Publications Office of the European Union.

Feist, G. J. 1998. A meta-analysis of personality in scientific and artistic creativity. Personality and Social Psychology Review 2(4): 290-309.

Furnham, A. and V. Bachtiar. 2008. Personality and intelligence as predictors of creativity. Personality and Individual Differences 45(7): 613-617.

Garrison, D. R. and H. Kanuka. 2004. Blended learning: uncovering its transformative potential in Higher Education. Internet and Higher Education 7: 95-105.

Geoff, M. 2009. The art of public strategy: Mobilizing power and knowledge for the common good. Oxford: Oxford University Press.

George, J. M. and J. Zhou. 2001. When openness to experience and conscientiousness are related to creative behaviour: An interactional approach. Journal of Applied Psychology 86(3): 500-513.

Grief, A. 2016. Family structure, institutions, and growth: the origins and implications of western corporations. http://web.stanford.edu/ avner/Greif_Papers/2006\%20AER\%20Families\%20and \%20Corporations.pdf (Accessed 8 January 2017).

Hage, J. and M. Meeus. 2006. Innovation, science, and institutional change: A research handbook, Oxford: Oxford University Press.

Hämäläinen, T. J. 2007. Social innovation, structural adjustment and economic performance. In Social innovations, institutional change and economic performance: Making sense of structural adjustment processes in industrial sectors, regions and societies, ed. T. Hämäläinen and Risto Heiskala. Edward Elgar, Cheltenham.

Hämäläinen, T. 2013. Towards a sustainable well-being society. Erweco, Helsinki, 2014. ISBN 978951-563-879-3.

Haynes, C. 2002. Innovations in interdisciplinary teaching. West port, CT, American Council on Education: ORYX.

Heher, A. D. 2006. Return on investment in innovation: Implications for institutions and national agencies. Journal of Technology Transfer 31: 403-414. 
Helliwell, J. F. and R. D. Putnam. 2004. The social context of well-being. Philosophical Transactions of the Royal Society of London, Series B 359: 1435-1446.

Hollinsworth, R. 2006. A path-dependent perspective on institutional and organizational factors shaping major scientific discoveries. New York: Oxford University Press.

Jakovljevic, M. 2013. A model of creativity, innovation and invention MCII for entrepreneurial engineers. In Knowledge management innovations for interdisciplinary education: Organizational applications, ed. S. Buckley and M. Jakovljevic. USA: IGI Global Publisher.

Jakovljevic, M. 2018. Criteria for innovation in higher education. African Education Review 2018. doi: 0.1080/18146627.2017.1369855. Informa UK (Taylor \& Francis) [in print].

Jewkes, J., D. Sawers and R. Stillerman. 1969. The successes of invention. London: MacMillan.

Johnson, P. S. 1975. The economic invention and innovation. London, UK: Martin Robertson \& Company.

Jones, C. 2010. Interdisciplinary approach - advantages, disadvantages, and the future benefits of interdisciplinary studies. http://dc.cod.edu/cgi/viewcontent.cgi?article=1121andcontext=essai (Accessed 11 Nov 2015).

Kahn, M., N. Vlotman, C. Steyn and M. van der Schyff. 2012. Innovation policy and higher education in South Africa: Addressing the challenge. South African Review of Sociology: 176-190. http://dx.doi.org/10.1080/21528586.2007.10419174

Kaplan, D. 2009. The economics of intellectual property in South Africa, WIPO. http://www.wipo.int/ portal/en/index.html (Accessed 12 November 2016).

King, N. and N. Anderson. 2002. Managing innovation and change: A critical guide for organizations. $2^{\text {nd }}$ Edition. Thomson.

Kleinberg, Ethan. 2008. "Interdisciplinary studies at a crossroads.” Association of American Colleges and Universities. http://www.eric.ed.gov/ERICDocs/data/ericdocs2sql/content_storage_01 /0000019b/80/29/92 /84.pdf

Kruss, G. 2005. Harnessing innovation potential? Institutional approaches to industry-higher education research partnerships in South Africa. Industry \& Higher Education. HSRC Library: Shelf number 3937.

Kruss, G. 2010. Towards dialogue: Higher education's role in innovation and social engagement. Review of Education, Skills Development and Innovation (RESDI). HSRC Library: Shelf number 6718. Pretoria. South Africa.

Laursen, K. and A. Salter. 2006. Open for innovation: The role of openness in explaining innovation performance among UK manufacturing firms. Strategic Management Journal 27(2): 131-150.

Lubango, L. M. and A. Pouris. 2009. Is patenting activity impeding the academic performance of South Africa University researchers? Technology in Society Vol xxx: 1-10.

Lubart, T. I. 2001. Models of the creative process: Past, present, and future. Creativity Research Journal 13: 295-308.

Manzini, S. T. 2012. The national system of innovation concept: An ontological review and critique. S Afr Sci. 108(/9/10), Art. \#1038, 7 pages. http://dx.doi.org/10.4102/sajs. V108i9/10.1038.

Martins, E. and F. Terblanche. 2003. Building organisational culture that stimulates creativity and innovation. European Journal of Innovation Management 6(1): 64-74.

McAdams, D. P. 1995. What do we know when we know a person? Journal of Personality 63: 365396.

McCrae, R. R. and P. T. Costa. 1987. Validation of the five factor model of personality across instruments and observers. Journal of Personality and Social Psychology 52: 81-90.

McCrae, R. R. and P. T. Costa. 1997. Personality trait structure as human universal. American Psychologist 52: 509-516.

McLean, L. D. 2005. Organizational culture's influence on creativity and innovation: A review of the 
literature and implications for human resource development. Advances in Developing Human Resources 7: 226-246.

Meso, P. and R. Smith. 2000. A resource-based view of organizational knowledge management systems. Journal of Knowledge Management 4(3): 224-234. doi: I 0.1108/136732700 I 0350020.

Moses, C., M. Moses, X. Sithole, W. Blankley, D. Labadarios, H. Makelane and N. Nkobole. 2008. The state of innovation in South Africa: Findings from the South African National Innovation Survey, S Afr J Sci 108 (7/8): 1-5.

Neethling Brain Instruments. 2000. www.thewholebrain.com (Accessed 7 October 2016).

Oanda, I. O. 2013. The development of higher education in Africa: Prospects and challenges. International Perspectives on Education and Society 21: 69-97.

OECD see Organisation for Economic Co-operation and Development.

Organisation for Economic Co-operation and Development. 2005. European Commission. Oslo manual. $3^{\text {rd }}$ Edition. Paris: OECD Publishing. http://www.oecd.org/ (Accessed 6 October 2016).

Organisation for Economic Co-operation and Development. 2011. How's life? Measuring well-being, OECD, Paris.

Organisation for Economic Co-operation and Development. 2012. "New approaches to economic challenges - a framework paper", Note by the Secretary General. Paris, Offer, Avne. https://www.oecd.org/general/50452415.pdf (Accessed 7 March 2017).

Organisation for Economic Co-operation and Development. 2013. Innovation, Higher Education and Research for Development (IHERD) http://oecd.org/sti/innovationhighereducation andresearchdevelopmentiherd.htm

Organisation for Economic Co-operation and Development. 2017. Science, technology and innovation: Recent policy development in South Africa. www.oecd.org/science/inno/2112129.pdf (Accessed 4 November 2017).

Olakitan, O. O. 2011. An examination of the impact of selected personality traits on the innovative behaviour of entrepreneurs in Nigeria. International Business and Management 3(2): 112-121.

Paul, S. A. and C. Heckscher. 2007. Towards collaborative community. In The firm as a collaborative community: Reconstructing trust in the knowledge economy, ed. Charles Hecksher and Paul S. Adler. Oxford University Press, Oxford.

Postiglione, G. 2011. The rise of research universities: The Hong Kong University of Science of Technology. In The road to academic excellence: The making of world-class research universities, ed. P. G. Altbach and J. Salmi, 63-100. Washington, DC: World Bank.

Pouris, A. and A. Pouris. 2011. Patents and economic development in South Africa: Managing intellectual property rights. S. Afr. j. sci. 107(11-12): 1-10.

Rangaa, M. and H. Etzkowitz. 2016. Triple helix systems: An analytical framework for innovation policy and practice in the knowledge society. http://triplehelix.stanford.edu/images/ Triple_Helix_Systems.pdf (Accessed 3 May 2016).

Razak, A. and M. Saad. 2007. The role of universities in the evolution of the Triple Helix culture of innovation network: The case of Malaysia. International Journal of Technology Management and Sustainable Development 6(3): 211-225.

Rogers, C. 1961. On becoming a person. Boston: Houghton Mifflin.

Rothmann, S. and E. P. Coetzer. 2003. The big five personality dimensions and job performance. $S A$ Journal of Industrial Psychology 29(1): 68-74.

Senker, J. 2016. Tacit knowledge and models of innovation. Science Policy Research Unit, University of Sussex Brighton BN1 9RF, UK.

Sharma, M., U. Kumar and L. Lalande. 2006. Role of university technology transfer offices in university technology commercialization: Case Study of the Carleton University Foundry Program. Journal of Services Research Special Issue 6: 109-139. 
Shavinina, V. S. 2003. Understanding innovation: Some important issues. London: Elsevier Science.

Shelton, K. A. and T. Arciszewski. 2007. Formal innovation criteria. International Journal of Computer Applications in Technology IJCAT 30(1/2).

Sherry, L. 2003.Sustainability of innovations. Journal of Interactive Learning Research 13(3): 209-36.

Sibanda, M. 2007. The state of patenting in South Africa. Special Report. Pretoria: Innovation Fund.

Stavridou, A. and A. Furnham. 1996. The relationship between psychoticism, trait-creativity and the attentional mechanism of cognitive inhibition. Personality and Individual Differences 21(1): 143153.

Sung, S. Y. and J. N. Choi. 2009. Do big five personality factors affect individual creativity? The moderating role of extrinsic motivation. Social Behaviour and Personality 37(7): 941-956.

UN see United Nations.

United Nations. 2015. Transforming our world: The 2030 agenda for sustainable development. UN, 2015.

Utterback, J. M. 2002. The dynamics of innovation: In the internet and the university, London: Aspen Press.

Utterback, J. M. and W. J. Abenathy. 1975. A dynamic model of process and product innovation. OMEGA. The Int. JI of Mgrnt Sci. 3(6). UK: Pergamon Press.

Varis, T. 2007. Universities and regional development: The challenge in the era of the globalisation of higher education. New technologies and innovation in higher education and regional development. Monograph. www.uoc.edu (Accessed 8 April 2016).

Wolfradt, U. and J. E. Pretz. 2001. Individual differences in creativity: Personality, story writing, and hobbies. European Journal of Personality 15(4): 297-310.

Woodman, R. W., J. E. Sawyer and R. W. Griffin. 1993. Towards a theory of organizational creativity. Academy of Management Review 18(2): 293-321.

Zhou, J. and J. M. George. 2003. Awakening employee creativity: The role of leader emotional intelligence. The Leadership Quarterly 14: 545-568. doi: I 0.10 16/S I 048-9843(03)00051-1. 